\title{
Impact of Organizational Culture on Transformational Leadership and Organizational Performance
}

\author{
Ahmed Hamoud Al-Shibami, Nayef Alateibi, Mohammed Nusari, Ali Ameen, Gamal S. A. Khalifa, \\ Amiya Bhaumik
}

\begin{abstract}
This study employs structural equations modeling via PLS to analyze the 392 valid questionnaires in order to assess the proposed model that is based on the transformational leadership characteristics to identify its effect on the performance of organizations, besides assessing the moderating role of organizational culture in the government sector in the United Arab Emirates. The main independent construct is transformational leadership as a second-order construct of idealized influence, inspirational motivation, intellectual stimulation, and individualized consideration. The dependent construct covers organizational performance in terms of learning \& growth and internal process. Whereas power distance representing the organizational culture as a moderating variable. The study will describe the relations among the various constructs. Our work has improved our insight into the importance of transformational leadership and organizational culture. Results indicated that the independent variable significantly predicted performance, in addition to power distance having a significant moderating role between transformational leadership and internal process, but not between transformational leadership and learning \& growth. The proposed model explained $40.8 \%$ of the variance in learning $\&$ growth and $29.8 \%$ in internal process.
\end{abstract}

Keywords : Transformational leadership; organizational culture; power distance; organizational performance; UAE..

\section{INTRODUCTION}

The concept of leadership has been of keen interest for several decades and several definitions have been attributed to it in this regard. Previous researchers defined leadership as an organizationally useful behavior which is exhibited by a member of the organization to other members of the organization. Even long before that, the concept had attracted the views of the scholars who were in the direction

Revised Manuscript Received on September 25, 2019

Ahmed Hamoud Al-Shibami, Faculty of Business and Accountancy, Lincoln University College, Selangor, Malaysia

Nayef Alateibi, Faculty of Business and Accountancy, Lincoln University College, Selangor, Malaysia

Mohammed Nusari, Faculty of Business and Accountancy, Lincoln University College, Selangor, Malaysia

Ali Ameen, Faculty of Business and Accountancy, Lincoln University College, Selangor, Malaysia

Gamal S. A. Khalifa, Faculty of Hospitality and Tourism, Lincoln University College (LUC), Selangor, Malaysia

Amiya Bhaumik, Faculty of Hospitality and Tourism, Lincoln University College (LUC), Selangor, Malaysia that leadership must be seen as a function or process rather than as an attribute of a predetermined role as predominantly observed.

Transformational leadership and their overarching role to induce success in the face of change and environmental turbulence by enhancing and redefining organizational performance and business processes is imperative to the present investigation. Many experts agreed that transformational leadership has become a prevalent method of determining the impact leaders have on organizational performance and underlying business processes. Many also stressed that transformational leadership has over the years showed a close association with the determinants of organizational performance.

It may be continued that most of the attention researchers have offered to transformational leadership has been due to the notion that leadership and culture are both closely associated with the performance of organizations. Some also stressed that transformational leadership has over the years showed a close association with the determinants or organizational performance. There is growing consensus that transformational leadership has become a prevalent method of determining the impact leaders have on organizational culture and underlying business processes. There is however limited research into the exact nature of the association between transformational leadership and the role it plays in organizational change.

Over the last couple of decades, the United Arab Emirates (UAE) public sector has experienced a substantial change in tune with globalization. There is no doubt that the country is one of the fastest growing countries not only in the Middle East but globally with the implementation of highly innovative infrastructural and governance systems. As the UAE strives to position itself and the public sector as a service-oriented economy, this has instigated a number of restructuring in the area of classical public administration. Restructuring and transformations have witnessed public sector institutions changing towards more competitive and customer-centric platforms. Ultimately, the public sector of the UAE has changed in scope over the last few years and continues to implement changes in a manner that is much is similar to the private sector in contemporary times.

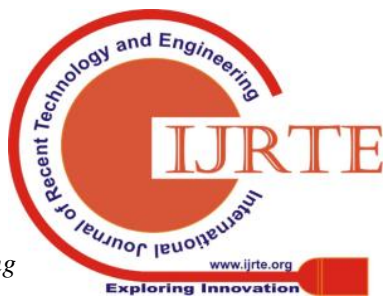


A study also mentioned that the UAE public sector seeks to offer customer-centric services and is experiencing an ongoing change in various sectors. As a result of this pressure to change, the public-sector organizations have shown an increased interest in adopting transformational leadership that will help achieve results in this regard.

\section{LiteratURE REVIEW}

\section{A. Organizational Performance (OP)}

Organizational performance is among the most important variables in the management research that assesses the overall organizational performance [1]. It is the measure of standard or prescribed indicators of effectiveness, efficiency, and environmental responsibility such as cycle time, productivity, waste reduction, and regulatory compliance. It allows the researchers and managers to evaluate organizations over time and compare them with its rivals [2]. This study will examine performance in terms of two factors namely, learning \& growth, and internal process. Leaning \& growth refers to how staff are trained and educated, gain and capture knowledge Kaplan \& Norton [3] noted that learning and growth come from three principal sources: people, systems and organizational procedures. As for internal process, it refers to what processes must an organization excels at, to achieve its public service objectives, which will have the greatest effect on public satisfaction and its financial objectives. The critical processes enable the department to deliver the expectations of the public and satisfy the leaders of the country expectations of high outcomes [3].

\section{B. Transformational Leadership (TL)}

Transformational leadership has been widely accepted as the ideal leadership style in contemporary organizations. This form of leadership has gained recognition due to the recognizable impact of transformational leadership and its ability to achieve organizational outcomes such as employee satisfaction and organizational performance. It is widely accepted that transformational leadership has the peculiar ability to instigate higher order need $[4,5]$. Another study added that transformational leadership has the ability to motivate employees and generating positive emotions, the creation of an inspirational vision for the vision and directing followers towards achieving these objectives. Drawing on proposed dimensions of transformational leadership by several authors, four dimensions of transformational leadership were derived which are fundamental to the present study: Idealized Influence (II), Inspirational Motivation (IM), Intellectual Stimulation (IS) and Individualized Consideration (IC). Hence, two hypotheses were suggested:

H1: Transformational leadership influence has a positive influence on learning and growth.

$\mathrm{H} 2$ : Transformational leadership has a positive infleunce on internal process.

\section{Organizational Culture (OC)}

Culture has often taken a variety of perspectives in management and academic research. The number of investigation and models of culture in research have led to the evolution of the concept of culture as one of the most diversified subjects in the same or even above that of leadership theories. Ultimately, it was also mention that national value cultures are often related to and inseparable from organizational culture and individual culture. Several attempts have been made to provide a definition for organizational culture. Some researchers considered organizational culture as the meanings embedded in the actions of organizational commerce and discourse. An earlier and popular definition of organizational culture described it as a collection of behaviors that are expected within a group and are generally accepted by the group's members. Years on after that, organizational culture also began to be considered as the norms of an organization. The organizational culture is very vital and determines organizational climate pointing out that it is a very important part of any successful organization. Further, culture has equally been observed as a main effect or as a moderator in several investigations [6-8].

Organizational culture plays a great role in the functionality of an organization, therefore, it does not only hold interest for researchers and scholars but it is also of great significance to companies and their managers. The organizational culture is one of the most complicated dimensions of change management and it is as well made up of formal and informal components. It is, however, important to note that organizational cultures are not static or uniform, but they actually evolve as time moves on. Culture factor is represented by several aspects including power distance which this study will utilize as in the hypotheses below:

H3: Power distance strengthens the transformational leadership's impact on learning and growth.

H4: Power distance strengthens the transformational leadership's impact on internal process

\section{RESEARCH METHOD}

\section{A. Overview of the Proposed Research Model}

The relationships between constructs hypothesized in the conceptual framework have been adapted from the relevant literature in the subject matter. Fig 1 shows the proposed model that contains transformational leadership (idealized influence, inspirational motivation, intellectual stimulation, and individualized consideration) to predict organizational performance in terms of learning \& growth, and internal process, besides power distance as a moderating variable. The proposed model assesses the relationship between the aforementioned constructs among government employees in the United Arab Emirates. The proposed conceptual framework has four hypotheses to be tested. 


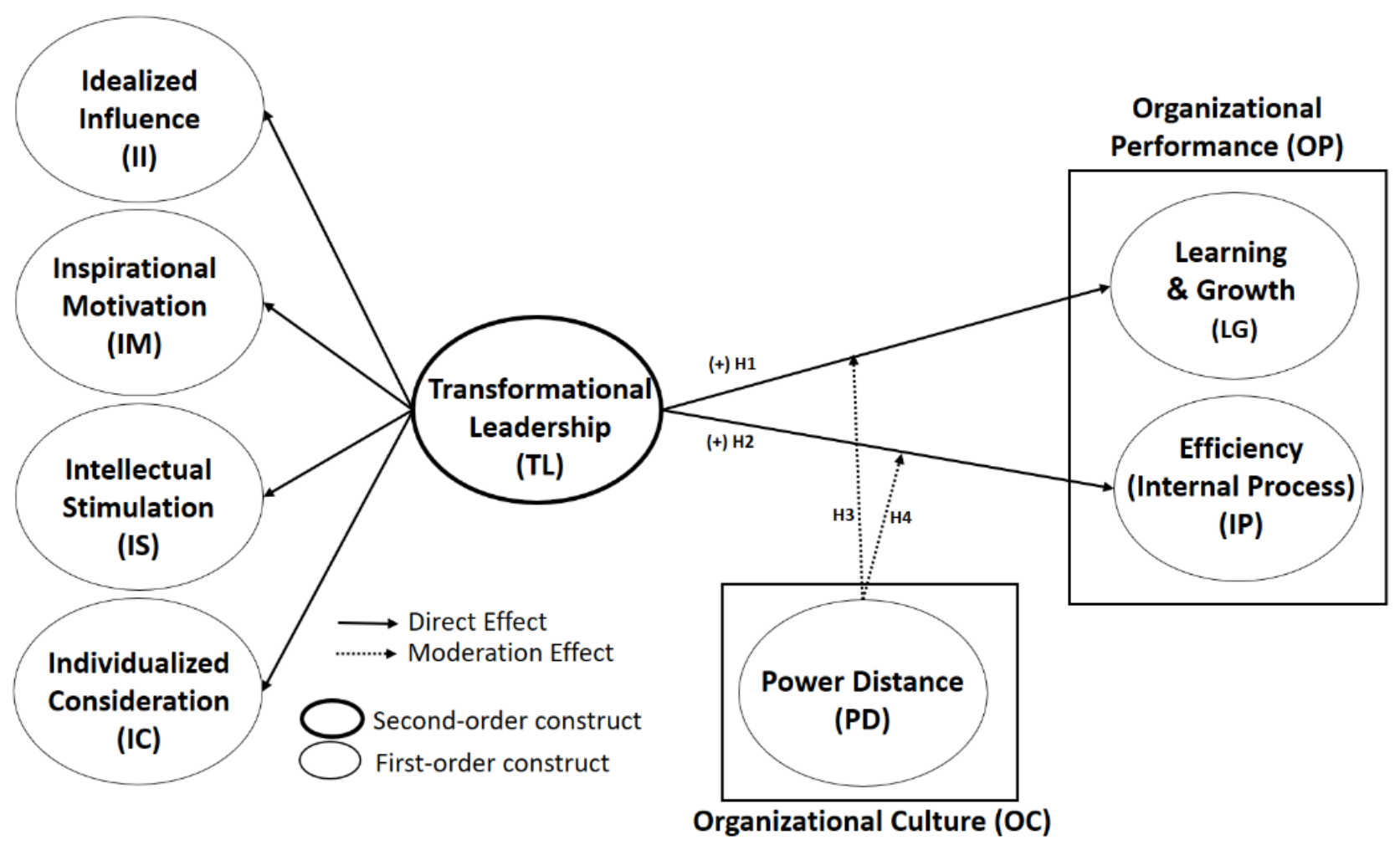

Fig. 1: PLS algorithm results

\section{B. Development of Instrument}

The development of an instrument for this study included a 35-item questionnaire, and based on the performance literature, the study applied a multi-item Likert scale [9]. Constructs were measured using a Likert scale which recommended in the previous studies [10-12], with 5 being 'Strongly Agree' and 1 being 'Strongly Disagree'. Given the fact that the respondents were Arabic-speakers, it is required to have the questionnaires translated from English to Arabic in a precise way. Thus a back translation was applied, which is a procedure widely used in a cross-cultural survey. Previous studies were used to get a validated measurement of the variables in this study (Appendix A). The guidelines of Hayduk \& Littvay [13] were followed while formulating the study constructs.

\section{Data Collection}

The data was collected by delivering a self-administered questionnaire 'in-person' from April 2017 until August 2017 to government employees. Out of 700 distributed questionnaires, 423 returned with respondent's responses. Of these 392 were filtered out for the current study analysis [14, 15]. Compared to the relevant literature the $60.43 \%$ response rate of this study is considered very good. The number of the deleted questionnaires was 31 including a 21 missing data cases of more than $15 \%$ of the questions, and 3 cases as outliers, and 7 cases that have a straight lining.

\section{Data Analysis ANd Results}

PLS SEM-VB was implemented to conduct this study along with the usage of the SmartPLS 3.0 software [16]. A two-stage analytical method [17] comprising (i) measurement model assessment (validity and reliability) and (ii) structural model assessment (testing the hypothesized relationships) was used after conducting the descriptive analysis. This two-stage analytical method consisting of a measurement model and a structural model assessment is superior to a one-step assessment [18, 19]. While the measurement model explains the measurement of each construct, the structural model defines the relationship between the variables in the structural model [20].

\section{A. Descriptive analysis}

In table 1, the values of mean and standard deviation are illustrated as follows: Idealized influence mean score of 3.13 out of $5.0(\mathrm{SD}=1.25)$ denoted that the respondents agreed that leaders instill pride in others for being associated with them, go beyond self-interest for the good of the group, act in ways that build others' respect for them, and talk about their most important values and beliefs. Inspirational motivation mean score of 2.96 out of 5.0 ( $\mathrm{SD}=1.11$ ) denoted that the respondents agreed that leaders talk optimistically about the future, talk enthusiastically about what needs to be accomplished, articulate a compelling vision of the future, and express confidence that goals will be achieved. Intellectual stimulation mean score of 2.94 out of 5.0 (SD = 1.12) denoted that the respondents agreed that leaders re-examine critical assumptions to question whether they are appropriate, seek differing perspectives when solving problems, get others to look at problems from many different angles, and suggest new ways of looking at how to complete assignments. Individualized consideration mean score of 3.32 out of 5.0, $(\mathrm{SD}=1.20)$ denoted that that the respondents agreed that leaders treat others as individuals rather than just as a member of a group, 
consider an individual as having different needs, abilities, and aspirations from others, seek a differing point of view when dealing with the organizational issues, and help others to develop their strengths. Learning \& growth mean score of 3.27 out of $5.0(\mathrm{SD}=1.13)$ denoted that the respondents agreed that the organization seeks to see what is new in the business world and apply it to their work, the organization is trying to facilitate the use of new technology to take advantage of its services, the Organization Includes the growth side and motivates individuals to assess their performance, and the Organization based foundations of scientific research to solve problems, and the organization interested in developing plans and projects for the development of its business and streamline procedures. Internal process mean score of 3.10 out of $5.0(\mathrm{SD}=1.17)$ indicating that the respondents agreed that the internal operations focus on transforming internal goals into reality, the internal operating processes focus on the quality of the services provided to the public, and Internal operations focuses on human resources, capacity development, business leadership and modern methods.

\section{B. Measurement Model Assessment}

Construct reliability and validity (consisting of convergent and discriminant validity) were utilized to test the measurement model. The individual Cronbach's alpha coefficients were examined to ascertain the reliability of each core variable in the measurement model (construct reliability). The values of all the individual Cronbach's alpha coefficients in this study were between 0.910 to 0.949 , which exceeded the suggested value of 0.7 [21]. The composite reliability (CR) were found to be between 0.931 to 0.960 that aided in assessing the construct reliability. It exceeded the 0.7 margin [22-24]. Therefore, as illustrated in Table 1, construct reliability has been satisfied as Cronbach's Alpha and CR were relatively error-free for all the constructs.

Assessment of Indicator reliability was done by using factor loadings. When the associated indicators have much in common, this is captured in the construct and indicated by high loadings on the construct. According to Hair et al. [19], values exceeding 0.50 indicate significant factor loadings. Table 1 exhibits that all items of the current research work had factor loadings higher than the recommended value of 0.5. There was an exception in terms of the items like LG7 and IP6, which were eliminated from the scale due to low loadings.

Average variance extracted (AVE) was found between 0.693 to 0.834 (more than 0.5 recommended limit) [19]. Therefore, all constructs have fulfilled the convergent validity satisfactorily, as illustrated in Table 1.

Table 1: Mean, standard deviation, loading, cronbach's Alpha, CR and AVE

\begin{tabular}{|c|c|c|c|c|c|c|c|}
\hline Constructs & Item & $\begin{array}{c}\text { Loading } \\
(>0.5)\end{array}$ & $\mathrm{M}$ & $\mathrm{SD}$ & $\begin{array}{c}\alpha \\
(>0.7)\end{array}$ & $\begin{array}{c}\mathrm{CR} \\
(>0.7)\end{array}$ & $\begin{array}{c}\text { AVE } \\
(>0.5)\end{array}$ \\
\hline \multirow{4}{*}{$\begin{array}{l}\text { Idealized } \\
\text { Influence } \\
\text { (II) }\end{array}$} & II1 & 0.921 & \multirow{4}{*}{3.13} & \multirow{4}{*}{1.25} & \multirow{4}{*}{0.934} & \multirow{4}{*}{0.953} & \multirow{4}{*}{0.834} \\
\hline & II 2 & 0.917 & & & & & \\
\hline & II3 & 0.907 & & & & & \\
\hline & II4 & 0.907 & & & & & \\
\hline \multirow{4}{*}{$\begin{array}{l}\text { Inspirational } \\
\text { Motivation } \\
\text { IM) }\end{array}$} & IM1 & 0.894 & \multirow{4}{*}{2.96} & \multirow{4}{*}{1.11} & \multirow{4}{*}{0.910} & \multirow{4}{*}{0.937} & \multirow{4}{*}{0.788} \\
\hline & IM2 & 0.896 & & & & & \\
\hline & IM3 & 0.891 & & & & & \\
\hline & IM4 & 0.868 & & & & & \\
\hline \multirow{4}{*}{$\begin{array}{l}\text { Intellectual } \\
\text { Stimulation } \\
\text { (IS) }\end{array}$} & IS1 & 0.874 & \multirow{4}{*}{2.94} & \multirow{4}{*}{1.12} & \multirow{4}{*}{0.918} & \multirow{4}{*}{0.942} & \multirow{4}{*}{0.803} \\
\hline & IS2 & 0.902 & & & & & \\
\hline & IS3 & 0.912 & & & & & \\
\hline & IS4 & 0.896 & & & & & \\
\hline \multirow{4}{*}{$\begin{array}{l}\text { Individualized } \\
\text { Consideration } \\
\text { (IC) }\end{array}$} & IC1 & 0.908 & \multirow{4}{*}{3.32} & \multirow{4}{*}{1.20} & \multirow{4}{*}{0.925} & \multirow{4}{*}{0.947} & \multirow{4}{*}{0.816} \\
\hline & IC2 & 0.909 & & & & & \\
\hline & IC3 & 0.915 & & & & & \\
\hline & IC4 & 0.881 & & & & & \\
\hline \multirow{5}{*}{$\begin{array}{c}\text { Power } \\
\text { Distance } \\
\text { (PD) }\end{array}$} & PD1 & 0.857 & \multirow{5}{*}{2.90} & \multirow{5}{*}{1.09} & \multirow{5}{*}{0.935} & \multirow{5}{*}{0.951} & \multirow{5}{*}{0.795} \\
\hline & PD2 & 0.893 & & & & & \\
\hline & PD3 & 0.885 & & & & & \\
\hline & PD4 & 0.907 & & & & & \\
\hline & PD5 & 0.914 & & & & & \\
\hline
\end{tabular}




\begin{tabular}{|c|c|c|c|c|c|c|c|}
\hline \multirow{7}{*}{$\begin{array}{l}\text { Learning \& } \\
\text { Growth } \\
\text { (LG) }\end{array}$} & LG1 & 0.921 & \multirow{7}{*}{3.27} & \multirow{7}{*}{1.13} & \multirow{7}{*}{0.949} & \multirow{7}{*}{0.960} & \multirow{7}{*}{0.799} \\
\hline & LG2 & 0.915 & & & & & \\
\hline & LG3 & 0.902 & & & & & \\
\hline & LG4 & 0.906 & & & & & \\
\hline & LG5 & 0.851 & & & & & \\
\hline & LG6 & 0.865 & & & & & \\
\hline & LG7 & Deleted & & & & & \\
\hline \multirow{7}{*}{$\begin{array}{l}\text { Internal } \\
\text { Process } \\
\text { (IP) }\end{array}$} & IP1 & 0.860 & \multirow{7}{*}{3.10} & \multirow{7}{*}{1.17} & \multirow{7}{*}{0.910} & \multirow{7}{*}{0.931} & \multirow{7}{*}{0.693} \\
\hline & IP2 & 0.880 & & & & & \\
\hline & IP3 & 0.854 & & & & & \\
\hline & IP4 & 0.839 & & & & & \\
\hline & IP5 & 0.856 & & & & & \\
\hline & IP4 & Deleted & & & & & \\
\hline & IP5 & 0.692 & & & & & \\
\hline
\end{tabular}

Note: $\mathrm{M}=$ Mean; $\mathrm{SD}=$ Standard Deviation, $\alpha=$ Cronbach's alpha; $\mathrm{CR}=$ Composite Reliability, $\mathrm{AVE}=$ Average Variance Extracted.

- The measurement used is seven-point scale ranging from 1 (strongly disagree) to 5 (strongly agree).

- All the factor loadings of the individual items are statistically significant $(\mathrm{p}<0.01)$ except for the items LG7 and IP6 which eliminated from the scale due to low loadings.

Key: II: idealized influence, IM: inspirational motivation, IS: intellectual stimulation, IC: individualized consideration, LG: learning \& growth, IP: internal process, PD: power distance.

The extent that items differentiate among constructs or measure distinct concepts is shown by Discriminant validity. Cross-loadings, Fornell-Larcker, and heterotrait-monotrait ratio (HTMT) were used to assess the discriminant validity of the measurement model. Usually, cross-loadings are used as the first step in testing discriminant validity of the indicators. In this study the cross loading criterion was also found to be satisfied (Table 2).

Table 2: Results of discriminant validity by the cross loading

\begin{tabular}{|c|c|c|c|c|c|c|c|}
\hline & II & IM & IS & IC & PD & $\mathrm{LG}$ & IP \\
\hline II1 & 0.921 & 0.619 & 0.621 & 0.633 & -0.187 & 0.502 & 0.434 \\
\hline II 2 & 0.917 & 0.592 & 0.627 & 0.640 & -0.203 & 0.494 & 0.433 \\
\hline II3 & 0.907 & 0.569 & 0.644 & 0.597 & -0.168 & 0.490 & 0.446 \\
\hline II4 & 0.907 & 0.597 & 0.634 & 0.657 & -0.192 & 0.485 & 0.460 \\
\hline IM1 & 0.603 & 0.894 & 0.577 & 0.597 & -0.141 & 0.457 & 0.430 \\
\hline IM2 & 0.572 & 0.896 & 0.532 & 0.567 & -0.158 & 0.423 & 0.400 \\
\hline IM3 & 0.566 & 0.891 & 0.546 & 0.550 & -0.162 & 0.431 & 0.379 \\
\hline IM4 & 0.569 & 0.868 & 0.539 & 0.536 & -0.186 & 0.401 & 0.381 \\
\hline IS1 & 0.602 & 0.503 & 0.874 & 0.556 & -0.169 & 0.462 & 0.437 \\
\hline IS2 & 0.628 & 0.568 & 0.902 & 0.659 & -0.130 & 0.424 & 0.457 \\
\hline IS3 & 0.640 & 0.590 & 0.912 & 0.620 & -0.193 & 0.465 & 0.437 \\
\hline IS4 & 0.608 & 0.552 & 0.896 & 0.618 & -0.188 & 0.425 & 0.428 \\
\hline $\mathrm{IC} 1$ & 0.628 & 0.589 & 0.639 & 0.908 & -0.146 & 0.480 & 0.433 \\
\hline IC2 & 0.609 & 0.559 & 0.630 & 0.909 & -0.192 & 0.435 & 0.399 \\
\hline IC3 & 0.643 & 0.582 & 0.621 & 0.915 & -0.175 & 0.478 & 0.360 \\
\hline IC4 & 0.620 & 0.562 & 0.586 & 0.881 & -0.104 & 0.439 & 0.382 \\
\hline PD1 & -0.182 & -0.194 & -0.170 & -0.157 & 0.857 & -0.326 & -0.112 \\
\hline PD2 & -0.209 & -0.177 & -0.195 & -0.159 & 0.893 & -0.325 & -0.154 \\
\hline PD3 & -0.185 & -0.145 & -0.159 & -0.164 & 0.885 & -0.334 & -0.068 \\
\hline PD4 & -0.156 & -0.138 & -0.153 & -0.113 & 0.907 & -0.307 & -0.085 \\
\hline PD5 & -0.181 & -0.155 & -0.167 & -0.165 & 0.914 & -0.356 & -0.100 \\
\hline LG1 & 0.515 & 0.462 & 0.455 & 0.472 & -0.335 & 0.921 & 0.323 \\
\hline LG2 & 0.482 & 0.442 & 0.446 & 0.448 & -0.365 & 0.915 & 0.287 \\
\hline LG3 & 0.511 & 0.442 & 0.443 & 0.484 & -0.307 & 0.902 & 0.330 \\
\hline LG4 & 0.464 & 0.423 & 0.446 & 0.452 & -0.341 & 0.906 & 0.349 \\
\hline LG5 & 0.435 & 0.410 & 0.429 & 0.434 & -0.340 & 0.851 & 0.339 \\
\hline LG6 & 0.485 & 0.407 & 0.435 & 0.429 & -0.297 & 0.865 & 0.369 \\
\hline
\end{tabular}


The Moderating Role of Organizational Culture in the Relationship between Transformational Leadership and Organizational Performance

\begin{tabular}{l|lllllll}
\hline IP1 & 0.395 & 0.393 & 0.410 & 0.365 & -0.131 & 0.352 & $\mathbf{0 . 8 6 0}$ \\
IP2 & 0.396 & 0.383 & 0.408 & 0.352 & -0.113 & 0.336 & $\mathbf{0 . 8 8 0}$ \\
IP3 & 0.462 & 0.399 & 0.440 & 0.392 & -0.128 & 0.284 & $\mathbf{0 . 8 5 4}$ \\
IP4 & 0.406 & 0.383 & 0.411 & 0.352 & -0.071 & 0.306 & $\mathbf{0 . 8 3 9}$ \\
IP5 & 0.385 & 0.341 & 0.416 & 0.373 & -0.107 & 0.287 & $\mathbf{0 . 8 5 6}$ \\
IP7 & 0.372 & 0.335 & 0.360 & 0.338 & -0.025 & 0.292 & $\mathbf{0 . 6 9 2}$ \\
\hline
\end{tabular}

Key: II: idealized influence, IM: inspirational motivation, IS: intellectual stimulation, IC: individualized consideration, LG: learning \& growth, IP: internal process, PD: power distance.

Table 3 displays the results for discriminant validity by using the Fornell-Larcker criterion (diagonal values). It shows a strong correlation between the constructs and their respective indicators as compared to the other constructs in the model $[25,26]$. The exogenous constructs exhibited a correlation of

Table 3: Results of discriminant validity by Fornell-Larcker criterion

\begin{tabular}{l|ccccc}
\hline & Factors & 1 & 2 & 3 & 4 \\
\cline { 2 - 6 } 1 & & IP & LG & PD & \\
2 & IP & $\mathbf{0 . 8 3 3}$ & & \\
3 & LG & 0.372 & $\mathbf{0 . 8 9 4}$ & $\mathbf{0 . 8 9 2}$ & \\
4 & PD & -0.117 & -0.37 & 0.217 & $\mathbf{0 . 7 7 8}$ \\
\hline
\end{tabular}

Key: TL: transformational leadership, LG: learning \& growth, IP: internal process, PD: power distance

The Fornell-Larcker criterion has been subjected to debate. because it does not have the ability to determine precisely the lack of discriminant validity in normal research situations (. Therefore, another technique has been suggested, namely the heterotrait-monotrait ratio (HTMT) of correlations based on the multitrait-multimethod matrix. HTMT has been used to test discriminant validity in this study. The discriminant validity poses certain issues when the HTMT value is higher than the $\mathrm{HTMT}_{0.90}$ value of 0.90 (Gold, Malhotra, Segar, \& Segars, 2001) or $\mathrm{HTMT}_{0.85}$ value of 0.85 [23], but Table 4 shows that all the HTMT values were less than the 0.85 , hence fulfilling the discriminant validity requirement.

Table 4: Results of discriminant validity by HTMT less than 0.85 [27]. So, all the exogenous constructs were in correlation with their discrimant validity.

\begin{tabular}{l|ccccc} 
& Factors & \multicolumn{1}{c}{1} & 2 & 3 & 4 \\
\cline { 3 - 5 } 1 & & IP & LG & PD & TL \\
2 & IP & & & & \\
3 & LG & 0.402 & & & \\
4 & PD & 0.125 & 0.392 & & \\
\hline
\end{tabular}

Key: TL: transformational leadership, LG: learning \& growth, IP: internal process, PD: power distance

\section{Structural Model Assessment}

The structural model can be tested by computing beta $(\beta)$, $\mathrm{R}^{2}$, and the corresponding $\mathrm{t}$-values via a bootstrapping procedure with a resample of 5,000 [20]. 


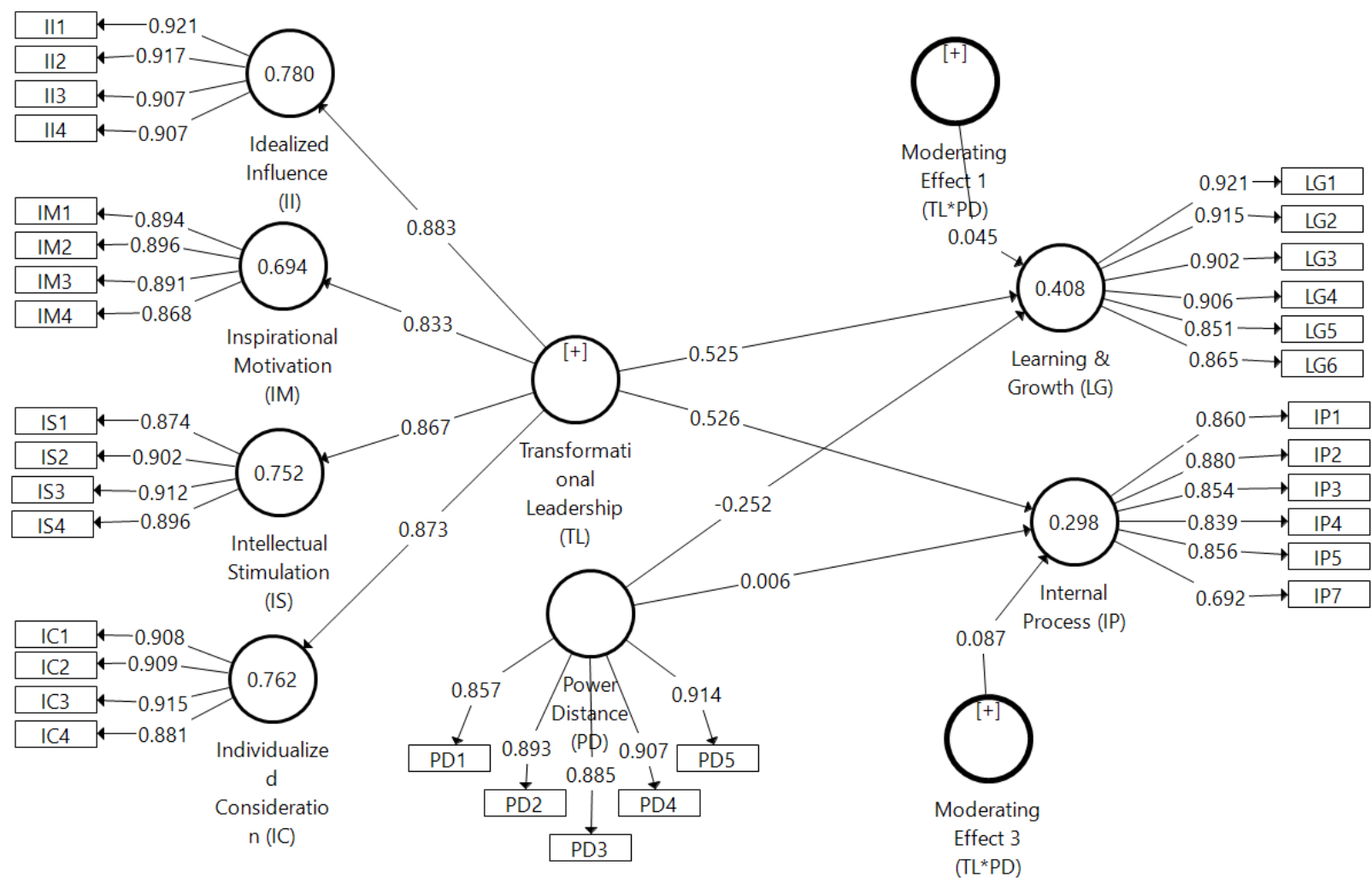

Key: TL: transformational leadership, II: idealized influence, IM: inspirational motivation, IS: intellectual stimulation, IC: individualized consideration, LG: learning \& growth, IP: internal process, PD: power distance.

Fig. 2: PLS algorithm results

\section{a. Direct Hypotheses Tests}

The structural model assessment, showing the results of the direct hypothesis tests, with 2 out of the 2 hypotheses are supported. Transformational leadership significantly predict learning \& growth and internal process. Hence, H1 and $\mathrm{H} 2$ are accepted with $(\beta=0.525, \mathrm{t}=12.346, \mathrm{p}<0.001)$ and $(\beta=0.526, \mathrm{t}=12.222, \mathrm{p}<0.001)$ respectively.

The strength of the relationship between exogenous and endogenous constructs are measured by the standardised path coefficients, which in this case show that the direct effects of transformational leadership on internal process is stronger than the influence of transformational leadership on learning \& growth.

Forty-one percent of the variance in learning \& growth is explained by transformational leadership, and thirty one percent of the variance in internal process is explained by transformational leadership. The values of $\mathrm{R}^{\mathbf{2}}$ have an acceptable level of explanatory power, indicating a substantial model [26, 28].

Effect sizes $\left(\mathrm{f}^{2}\right)$ was examined in this research. The effect size $\mathrm{f}^{2}$ ascertains the impact of an exogenous latent construct (whether substantial, moderate, or weak) on an endogenous latent construct. It is suggested that the change in $\mathrm{R}^{2}$ value is assessed [20]. The $\mathrm{f}^{2}$ value of 0.35 indicates large effects, 0.15 indicates medium effects, and 0.02 indicates small effects [28]. Table 5 displays the $\mathrm{f}^{2}$ results, indicating large effect sizes relationships.
In assessing the predictive relevance of the proposed research model, this study had applied the blindfolding procedure. This procedure should be employed on endogenous constructs with a reflective measurement only [21]. A particular endogenous construct of the proposed model has predictive relevance if the value of $\mathrm{Q}^{2}$ exceeded 0 . In this study, The $\mathrm{Q}^{2}$ value was greater than 0 , and hence, it can be concluded that the proposed model has an adequate predictive relevance (refer to Table 5). A relative measure of predictive relevance is indicated by $\mathrm{Q}^{2}$ values of 0.35 for large, 0.15 for medium, and 0.02 for small. The exogenous construct in this study was found to have large predictive relevance.

The existence of multicollinearity poses a problem as it indicates overlapping of the variance that the exogenous constructs explain in the endogenous construct. Therefore, it cannot justify each variance in the endogenous variable. Variance inflation factor (VIF) is commonly used as a measurement of the degree of multicollinearity. A value exceeding 10 for the largest VIF indicates a problem. Meanwhile, previous studies have suggested that a value exceeding 5 for the largest VIF indicates a multicollinearity problem [20]. When the VIF values are less than 5 there is no significant multicollinearity issue among the exogenous constructs in this study. In other words, there is no overlapping of the variance that the exogenous constructs explained in the endogenous construct. 
The Moderating Role of Organizational Culture in the Relationship between Transformational Leadership and Organizational Performance

Table 5: Structural path analysis result

\begin{tabular}{|c|c|c|c|c|c|c|c|c|c|c|}
\hline Hypothesis & Relationship & $\begin{array}{c}\text { Std } \\
\text { Beta }\end{array}$ & Std Error & t-value & $\mathrm{p}$-value & Decision & $\mathrm{R}^{2}$ & $\mathrm{f}^{2}$ & $\mathrm{Q}^{2}$ & VIF \\
\hline H1 & $\mathrm{TL} \rightarrow \mathrm{LG}$ & 0.525 & 0.042 & 12.346 & 0.000 & & $\begin{array}{c}0.4 \\
1\end{array}$ & 0.435 & $\begin{array}{c}0.30 \\
1\end{array}$ & 1.069 \\
\hline $\mathrm{H} 2$ & $\mathrm{TL} \rightarrow \mathrm{IP}$ & 0.526 & 0.043 & 12.222 & 0.000 & Supported & $\begin{array}{c}0.3 \\
0 \\
\end{array}$ & & $\begin{array}{c}0.18 \\
8 \\
\end{array}$ & 1.069 \\
\hline
\end{tabular}

Key: TL: transformational leadership, LG: learning \& growth, IP: internal process.

\section{b. Moderation Hypotheses Tests}

This study focuses on how the relationship between transformational leadership (predictor) on the one side and learning \& growth and internal process (outcome) changes as a function of power distance (moderator) on the other. The conceptual model of moderation in Figure 3.a. shows that a moderator variable is one that affects the relationship between two others. The statistical moderation model in Figure 3.b. shows how it conceptualizes moderation statistically: It predicts the outcome from the predictor variable, the proposed moderator and the interaction between the two. It is the interaction effect that tells whether moderation has occurred, but the predictor and moderator must be included as well for the interaction term to be valid. Researchers in many situations have a continuous (rather than a categorical) moderator variable that they believe can either strengthen or dampen a specific relationship between two latent variables and that moderators may also change the direction of relationships [20].

Awang [27] states that before introducing a moderator into a model, the effect of a predictor on its outcome must exist and be significant. Thus, when a moderator enters the model, the causal effects will change due to some "interaction effect" between the predictor and moderator variable just entered.

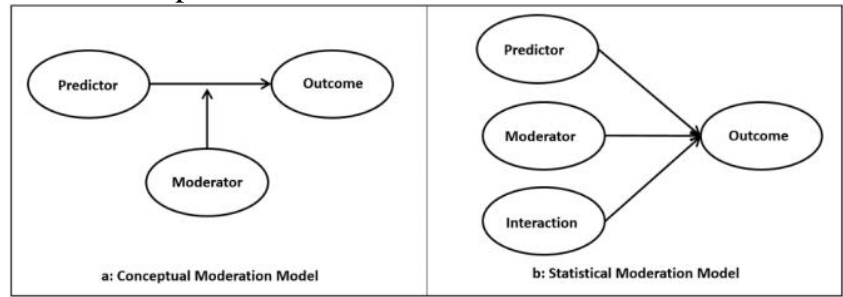

Fig. 2: : Conceptual and statistical moderation model Source: (Field, 2013)

As shown in Figure 2 and Table 6, three sub-hypotheses were tested for the two main hypothesis namely: (1) Testing the causal effect of the predictor on the outcome. (2) Testing the causal effect of moderating on the outcome. (3)Testing the causal effect of interaction (predictor*Moderating) on the outcome. The moderation assessment of this study was tested through hypotheses $\mathrm{H} 3$ and $\mathrm{H} 4$. A bootstrapping procedure with a resample of 5,000 was also performed to assess the interaction effect. The results in Figure 4 and Table 6 show that power distance moderates (strengthens) the impact of transformational leadership on the internal process $(\beta=0.087, \mathrm{t}=2.173, \mathrm{p}<0.05)$, so, $\mathrm{H} 4$ is accepted. However, $\mathrm{H} 3$ is rejected.

Table 6: Result of Moderating effects Hypotheses

\begin{tabular}{|c|c|c|c|c|c|c|}
\hline & & Std Beta & Std Error & t-value & p-value & Decision \\
\hline \multirow{3}{*}{$\mathrm{H} 3$} & H3.a: TL $\rightarrow$ LG & 0.525 & 0.042 & 12.346 & 0.000 & \multirow{3}{*}{ Not supported } \\
\hline & H3.b: $\mathrm{PD} \rightarrow \mathrm{LG}$ & -0.252 & 0.042 & 5.999 & 0.000 & \\
\hline & H3.c: $\mathrm{TL} * \mathrm{PD} \rightarrow \mathrm{LG}$ & 0.045 & 0.045 & 1.018 & 0.309 & \\
\hline \multirow{3}{*}{$\mathrm{H} 4$} & H4.a: TL $\rightarrow$ IP & 0.526 & 0.043 & 12.222 & 0.000 & \multirow{3}{*}{ Supported } \\
\hline & H4.b: $\mathrm{PD} \rightarrow \mathrm{IP}$ & 0.006 & 0.044 & 0.145 & 0.884 & \\
\hline & H4.c: $\mathrm{TL} * \mathrm{PD} \rightarrow \mathrm{IP}$ & 0.087 & 0.040 & 2.173 & 0.030 & \\
\hline
\end{tabular}

Note: TL: transformational leadership, LG: learning \& growth, IP: internal process, PD: power distance

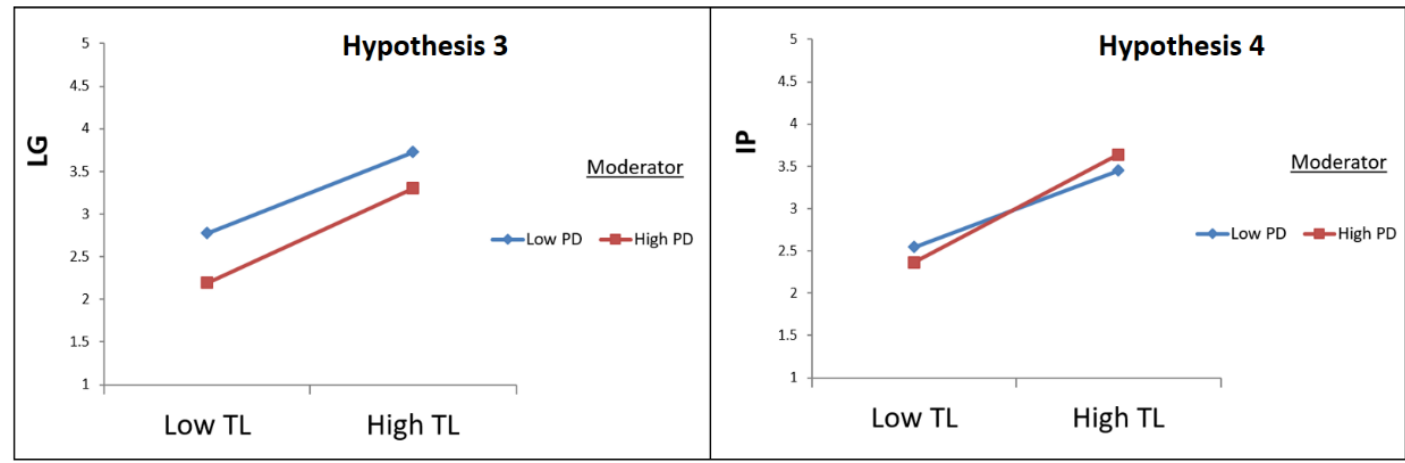

Fig. 4: : Moderating effects of the result of power distance 


\section{Discussion}

Based on the proposed model, this study improves the understanding of the role played by the characteristics of transformational leadership in terms of Idealized influence, Inspirational motivation, Intellectual stimulation, and Individualized consideration in predicting organizational performance in terms of learning \& growth, and internal processes, in addition to the moderating role of power distance among employees in the government sector in the United Arab Emirates, and highlights relevant implications. The discussions are further detailed in the following.

Transformational leadership was found to positively affect learning \& growth among employees of the government sector in the United Arab Emirates, this is supported by previous studies. It is explained by the fact that the more police department leaders give the sense of pride to their subordinates, always put their group before self-interest, act in a way that is being admired, spread the sense of optimism of the future, being more enthusiastic about what needs to be accomplished, lay out a vision of the future, tend to re-examine critical assumptions, look for multiple perspectives on problem-solving, treat others as individuals rather as just a group member, recognize the different needs, abilities of individuals, and help others to develop their skills, the more the organization explore new practices in business world, make use of new technology, utilize scientific research to solve problems, focuses on the development of human resource, motivate individuals to assess their performance, and constantly concerned with comparative performance measurement reference.

Likewise, Transformational leadership was found to positively affect internal process among employees of the government sector in the United Arab Emirates, this is supported by previous studies. It is explained by the fact that the more police department leaders give the sense of pride to their subordinates, always put their group before self-interest, act in a way that is being admired, spread the sense of optimism of the future, being more enthusiastic about what needs to be accomplished, lay out a vision of the future, tend to re-examine critical assumptions, look for multiple perspectives on problem-solving, treat others as individuals rather as just a group member, recognize the different needs, abilities of individuals, and help others to develop their skills, the more internal operations are focusing on fulfilling their internal goals, and on the quality of the services to the public, and develop channels of communication to facilitate the transfer of information.
Further, the results revealed that power distant does not have any moderation effect between transformational leadership and learning \& growth among employees of the government sector in the United Arab Emirates, which reflects the insignificance of this suggested hypotheses. The reason behind this might be the collectivism society that the UAE represents. It takes more than a person to make a change in the organizations in the United Arab Emirates. The organization itself as values and vision needs to have the transformational leadership aspect.

Finally, the results show that power distance has a moderating effect (strengthen) between transformational leadership and internal process among employees of the government sector in the United Arab Emirates, which confirms the moderation role that power distant has in this context. Simply stated, the more leaders give the sense of pride to their subordinates, always put their group before self-interest, act in a way that is being admired, spread the sense of optimism of the future, being more enthusiastic about what needs to be accomplished, lay out a vision of the future, tend to re-examine critical assumptions, look for multiple perspectives on problem-solving, treat others as individuals rather as just a group member, recognize the different needs, abilities of individuals, and help others to develop their skills, the more internal operations are focusing on fulfilling their internal goals, and on the quality of the services to the public, and develop channels of communication to facilitate the transfer of information. Given that Management is making decisions without consulting subordinates, using authority and power when dealing with subordinates, rarely as for employees' opinion, and keep important tasks away from employees.

\section{IMPLICATIONS, LIMITATIONS AND FUTURE DIRECTIONS}

The concept of transformational leadership is a newly emerging concept, and until now, it is not fully understood by most organizations in the UAE or the Arab world. This study represents a major foundation in elevating this concept within the Emirates public sector. Therefore, this study has provided a comprehensive illustration of how the role of internal leadership practices relates to individuals, groups, and organization performance and how it can be used in the best way to enhance overall performance. This research tested not only direct effects but, also, indirect effects through the moderating variable (power distant) in the public sector in

the UAE.
This study has
provided many benefits


for the public sector in UAE to view leadership practices as an enhancement for the organizational performance. This study has resulted in several recommendations. Public sector leaders should maintain and promote relationship connections amongst their employees and its clients to support the goals and strategy to raise the cohesion of informal organizations.

Among the limitations of this study is with regard to utilizing a cross-sectional design with questionnaires. A future research strategy that may overcome this limitation is one that involves longitudinal studies in which the flow of knowledge and performance can be followed over time. In addition, using objective measures, archival data for some variables, such as organizational performance, may give results that are more objective. In addition, observe changes in transformational leadership throughout the process. Therefore, future studies can develop a longitudinal study to find leadership differences in the performance of the organization

\section{CONCLUSION}

The purpose of this article was to examine the impact of transformational leadership on the organizational performance and the role of power distance in this impact among employees of the government sector in the United Arab Emirates. It has provided evidence from leading scholars in the field on the notion of 'transformational leadership' and regardless of various constraints to the study, the results have been encouraging, as it has managed to throw some lights on a new perspective. This study proposed a model which include transformational leadership (idealized influence, inspirational motivation, intellectual stimulation, and individualized consideration) as the independent variable and organizational performance (learning \& growth, and internal process) as the dependent variables. Besides power distance as a moderating variable. The results revealed that three out of four hypotheses are significant with the last one insignificant as power distance moderates the relationship between transformational leadership and internal process only. The independent variables significantly explain $40.8 \%$ of learning \& growth, and $29.8 \%$ of internal process. The implications of this study have been deliberated, some directions for future research have been suggested.

\section{APPENDIX}

\section{Appendix A}

Instrument for varibles

\begin{tabular}{|c|c|c|}
\hline Varible & Measure & Source \\
\hline $\begin{array}{l}\text { Idealized } \\
\text { Influence } \\
\quad \text { (II) }\end{array}$ & $\begin{array}{l}\text { II1: Leaders instill pride in others for being associated with them. } \\
\text { II2: Leaders go beyond self-interest for the good of the group. } \\
\text { II3: Leaders act in ways that build others' respect for them. } \\
\text { II4: Leaders talk about their most important values and beliefs. }\end{array}$ & \\
\hline $\begin{array}{l}\text { Inspirational } \\
\text { Motivation } \\
\quad \text { (IM) }\end{array}$ & $\begin{array}{l}\text { IM1: Leaders talk optimistically about the future. } \\
\text { IM2: Leaders talk enthusiastically about what needs to be accomplished. } \\
\text { IM3: Leaders articulate a compelling vision of the future. } \\
\text { IM4: Leaders express confidence that goals will be achieved. }\end{array}$ & \\
\hline $\begin{array}{l}\text { Intellectual } \\
\text { Stimulation } \\
\text { (IS) }\end{array}$ & $\begin{array}{l}\text { IS1: Leaders re-examine critical assumptions to question whether they are appropriate. } \\
\text { IS2: Leaders seek differing perspectives when solving problems. } \\
\text { IS3: Leaders get others to look at problems from many different angles. } \\
\text { IS4: Leaders suggest new ways of looking at how to complete assignments. }\end{array}$ & \\
\hline $\begin{array}{l}\text { Individualize } \\
\mathrm{d} \\
\text { Consideration } \\
\quad \text { (IC) }\end{array}$ & $\begin{array}{l}\text { IC1: Leaders treat others as individuals rather than just as a member of a group. } \\
\text { IC2: Leaders consider an individual as having different needs, abilities, and aspirations } \\
\text { from others. } \\
\text { IC3: Leaders seek a differing point of view when dealing with the organizational issues. } \\
\text { IC4: Leaders help others to develop their strengths. }\end{array}$ & \\
\hline $\begin{array}{c}\text { Power } \\
\text { Distance } \\
\text { (PD) }\end{array}$ & $\begin{array}{l}\text { PD1: Managers should make most decisions without consulting subordinates } \\
\text { PD2: It is frequently necessary for a manager to use authority and power when dealing } \\
\text { with subordinates. } \\
\text { PD3: Managers should seldom ask for the opinions of employees. } \\
\text { PD4: Employees should not disagree with management decisions. } \\
\text { PD5: Managers should not delegate important tasks to employees }\end{array}$ & \\
\hline
\end{tabular}


Learning and LG1: Organization seeks to see what is new in the business world and apply it to their Growth work.

LG its services.
of its

LG3: The Organization based foundations of scientific research to solve problems.

LG4: The Organization focuses on human resource development and performance.

LG5: Organization Includes the growth side and motivates individuals to assess their performance.

LG6: The Organization interested in developing plans and projects for the development of its business and streamline procedures.

LG7: The Organization concerned with comparative references outstanding performance measurement.

Internal IP1: The internal operations focuses on transforming internal goals into reality

Process IP2: Satisfactory performance of the Organization is due to top management decisions

(IP) and their applications.

IP3: The internal operating processes focus on the quality of the services provided to the public.

IP4: The internal operating processes focus on human resources and capacity development.

IP5: Internal operations focuses on business leadership and modern methods.

IP6: Internal operating processes established the organizational structure and describe

the Organization's functions.

IP7: Internal operations develop channels of communication to facilitate the transfer of information.

\section{REFERENCES}

[1] Gavrea, L. Ilies \& R. Stegerean (2011). Determinants of organizational performance: The case of Romania. Management \& Marketing, 6(2), pp. 285-300.

[2] P. J. Richard, T. Devinney, G. Yip \& G. Johnson, (2009). Measuring Organizational Performance: Towards Methodological Best Practice. $\begin{array}{llll}\text { Journal of } & \text { Management }\end{array}$ https://doi.org/10.1177/0149206308330560

[3] R. S. Kaplan \& D. P. Norton (2005). The Balanced Scorecard: Measures That Drive Performance. Harvard Business Review, (July-August).

[4] S. Alkhateri, A. E. Abuelhassan, G. S. A. Khalifa, M. Nusari \& A. Ameen, (2018). The Impact of perceived supervisor support on employees turnover intention : The Mediating role of job satisfaction and affective organizational commitment. International Business Management, 12(7), pp. 477-492. http://doi.org/10.3923/ibm.2018.477.492

[5] Ameen, H. Almari \& O. Isaac, (2019). Determining Underlying Factors that Influence Online Social Network Usage Among Public Sector Employees in the UAE. In Fathey M. Faisal Saeed, Nadhmi Gazem (Ed.), Recent Trends in Data Science and Soft Computing. IRICT 2018. Advances in Intelligent Systems and Computing (Recent Tre, Vol. 843, pp. 945-954). Springer Nature Switzerland AG: Springer International Publishing. http://doi.org/10.1007/978-3-319-99007-1

[6] Ameen \& K. Ahmad, (2011). The Role of Finance Information Systems in anti financial corruptions: A theoretical review. In 11 International Conference on Research and Innovation in Information Systems (ICRIIS'11 (pp. 267-272). Ieee. http://doi.org/10.1109/ICRIIS.2011.6125725

[7] Ameen \& K. Ahmad, (2012). Towards Harnessing Financial Information Systems in Reducing Corruption : A Review of Strategies. Australian Journal of Basic and Applied Sciences, 6(8), pp. 500-509.

[8] Ameen \& K. Ahmad, (2013). A Conceptual Framework of Financial Information Systems to reduce corruption. Journal of Theoretical and Applied Information Technology, 54(1), pp. 59-72.

[9] C. Lee, J. O. Yoon \& I. Lee, (2009). Learners' acceptance of e-learning in South Korea: Theories and results. Computers and Education, 53(4), pp. 1320-1329. http://doi.org/10.1016/j.compedu.2009.06.014

[10] O. Isaac, Z. Abdullah, T. Ramayah \& M. Mutahar Ahmed, (2017). Examining the Relationship Between Overall Quality, User Satisfaction and Internet Usage: An Integrated Individual, Technological, Organizational and Social Perspective. Asian Journal of Information Technology, 16(1), pp. 100-124. http://doi.org/10.3923/ajit.2017.100.124

[11] O. Isaac, Z. Abdullah, T. Ramayah \& A. M. Mutahar, (2017). Internet usage , user satisfaction, task-technology fit , and performance impact among public sector employees in Yemen. The International Journal of

Information and Learning Technology, 34(3), pp. 210-241. http://doi.org/10.1108/IJILT-11-2016-0051

[12] O. Isaac, Z. Abdullah, T. Ramayah, A. M. Mutahar \& I. Alrajawy, (2017). Towards a Better Understanding of Internet Technology Usage by Yemeni Employees in the Public Sector: An Extension of the Task-Technology Fit (TTF) Model. Research Journal of Applied Sciences, 12(2), pp. 205-223. http://doi.org/10.3923/rjasci.2017.205.223

[13] L. A. Hayduk \& L. Littvay (2012). Should researchers use single indicators, best indicators, or multiple indicators in structural equation models? BMC Medical Research Methodology, 12(1), pp. 1-17. https://doi.org/10.1186/1471-2288-12-159

[14] G. Tabachnick \& L. S. Fidell, (2007). Using Multivariate Statistics. PsycCRITIQUES, 28, pp. 980. http://doi.org/10.1037/022267

[15] R. V Krejcie \& D. W. Morgan, (1970). Determining sample size for research activities. Educational and Psychological Measurement, 38, pp 607-610.

[16] M. Ringle, S. Wende, \& J.-M. Becker, (2015). SmartPLS 3 Bonningstedt: SmartPLS.

[17] J. C. Anderson \& D. W. Gerbing, (1988). Structural Equation Modeling in Practice: A Review and Recommended Two-Step Approach Psychological Bulletin, 103(3), pp. 411-423. http://doi.org/10.1037/0033-2909.103.3.411

[18] R. E. Schumacker \& R. G. Lomax, (2004). A Beginner's Guide to Structural Equation Modeling. New York: Lawrence Erlbaum.

[19] Hair, J. F., Black, W. C., Babin, B. J., \& Anderson, R. E. (2010) Multivariate Data Analysis. New Jersey.

[20] J. F. J. Hair, G. T. M. Hult, C. Ringle \& Sarstedt, A Primer on Partia Least Squares Structural Equation Modeling (PLS-SEM), 46 Long Range Planning 328 (2014). London: Thousand Oaks: SAGE. http://doi.org/10.1016/j.lrp.2013.01.002

[21] V. R. Kannana \& K. C. Tan, (2005). Just in time, total quality management, and supply chain management: understanding their linkages and impact on business performance. Omega: The International Journal of Management Science, 33(2), pp. 153-162.

[22] E. Werts, R. L. Linn \& K. G. Jöreskog, (1974). Intraclass reliability estimates: Testing structural assumptions. Educational and Psychological Measurement, 34(1), pp. 25-33.

[23] R. B. Kline, (2010). Principles and practice of structural equation modeling (3rd ed.). New York: The Guilford Press.

[24] Gefen, D. Straub \& M.-C. Boudreau, (2000). Structural equation modeling and regression: Guidelines for research practice. Communications of the Association for Information Systems, 4(1), pp. $1-79$. 
[25] C. Fornell \& D. F. Larcker, (1981). Evaluating structural equation models with unobservable variables and measurement error. Journal of Marketing Research, 18(1), pp. 39-50.

[26] W. W. Chin, (1998a). Issues and opinion on structural equation modeling. MIS Quarterly, 22(1), pp. 7-16.

[27] Z. Awang, (2014). Structural Equation Modeling Using AMOS. Shah Alam.Malaysia: University Teknologi MARA Publication Center.

[28] J. Cohen, (1988). Statistical Power Analysis for the Behavioral Sciences (2nd Editio). LawreAssociatesnce Erlbaum.

\section{AUTHORS PROFILE}

Ahmed Hamoud Al-Shibami profile which contains their education details, their publications, research work, membership, achievements, with photo that will be maximum $200-400$ words.

Nayef Alateibi profile which contains their education details, their publications, research work, membership, achievements, with photo that will be maximum $200-400$ words.

Mohammed Nusari profile which contains their education details, their publications, research work, membership, achievements, with photo that will be maximum 200-400 words.

Ali Ameen profile which contains their education details, their publications, research work, membership, achievements, with photo that will be maximum 200-400 words.

Gamal S. A. Khalifa profile which contains their education details, their publications, research work, membership, achievements, with photo that will be maximum 200-400 words.

Amiya Bhaumik profile which contains their education details, their publications, research work, membership, achievements, with photo that will be maximum 200-400 words. 